\title{
A morphological study of the action of equine anti- lipopolysaccharide plasma on gram-negative bacteria
}

\author{
S. L. GAFFIN and M.T. WELLS
}

Department of Physiology, University of Natal Medical School, P.O. Box 17039, Congella, 4013, South Africa

\begin{abstract}
Summary. Three strains of gram-negative bacteria-one each of Escherichia coli, Klebsiella pneumoniae and Enterobacter sp. - were treated with anti-lipopolysaccharide hyperimmune equine plasma (anti-LPS) or non-immune control plasma and examined by scanning electronmicroscopy. Within a few minutes of treatment with anti-LPS, bacteria were agglutinated. Evidence of cell membrane destruction was observed shortly thereafter and total cell disintegration and disruption occurred within 1-2 h. In contrast, non-immune plasma had no effect on cell morphology. This confirms the findings in previous microbiological studies that specific antibodies in anti-LPS bind to lipopolysaccharide (LPS endotoxin), and thereby initiate the destruction of gramnegative bacteria.
\end{abstract}

\section{Introduction}

Endotoxin (LPS, lipopolysaccharide), an integral part of the outer surface of gram-negative bacteria, is highly toxic to mammals. It is currently believed to be responsible for much of the morbidity and mortality associated with gram-negative bacteraemia (Fine, 1964). Conventional antibiotics do not affect LPS; moreover the liberation of large amounts from disintegrating bacteria may cause clinical deterioration due to endotoxic shock (Shenep et al., 1985).

A recent approach to therapy for gram-negative bacterial infections has been the administration of serum containing antibodies that bind to LPS, resulting in detoxification and opsonisation (Pudifin et al., 1985). It has also been shown that antibodies to LPS in equine plasma (anti-LPS), together with complement, kill pathogenic gram-negative bacteria (Wells et al., 1987; Wells and Gaffin, in press), but the nature of the morphological changes in bacterial structure were not clear.

In view of the bactericidal activity of anti-LPS, the present study was undertaken to examine the morphological changes resulting from anti-LPS treatment in three representative species of gramnegative bacteria by scanning electronmicroscopy.

\section{Materials and methods}

\section{Bacteria}

Three hospital isolates, one each of Escherichia coli, Klebsiella pneumoniae and Enterobacter sp., were obtained

Received 3 Sep. 1986; accepted 14 Nov. 1986. from the Department of Microbiology, King Edward VIII Hospital, Durban.

\section{Experimental procedure}

Nutrient broth was inoculated with each test strain and cultures were incubated at $37^{\circ} \mathrm{C}$ for $18 \mathrm{~h}$. Cells were harvested by centrifugation at $1500 \mathrm{~g}$ for $10 \mathrm{~min}$ and the bacterial pellets were washed twice with sterile, pyrogenfree saline and re-centrifuged. Bacterial counts were adjusted to $9 \times 10^{8} \mathrm{cfu} / \mathrm{ml}$. Two-ml volumes of anti-LPS or non-immune control plasma were incubated with $0.33 \mathrm{ml}$ of bacterial suspension and $0.66 \mathrm{ml}$ of saline, for up to $2 \mathrm{~h}$ at $37^{\circ} \mathrm{C}$. Samples were removed and centrifuged at $300 \mathrm{~g}$ for $5 \mathrm{~min}$. The residual bacterial pellet was prepared for scanning electronmicroscopy (SEM).

\section{SEM preparation}

Bacterial pellets were fixed by suspending in gluteraldehyde $2 \%$ and $0.2 \mathrm{M}$ cacodylate buffer, $p \mathrm{H} \mathrm{7.4}$. Fixed samples were processed in a critical point drying holder on a $0.6-\mu \mathrm{m}$ polycarbonate filter (Nucleopore Corp., Pleasanton, CA, USA). They were dehydrated through a graded series of alcohols to absolute alcohol. Thereafter, they were processed in a Hitachi HCP1 critical point dryer, mounted on aluminium stubs, and coated with gold-palladium in a Polaron E5100 sputter coater, to a thickness of less than $5 \mathrm{~nm}$. They were viewed in a Hitachi S520 Scanning Electronmicroscope used at accelerating voltages of $20 \mathrm{kV}$. Electronmicrographs were recorded with $70 \mathrm{~mm}$ Kodak PXP 220 film.

\section{Anti-LPS plasma}

This was prepared by plasmapheresis of horses suitably vaccinated by a proprietary procedure (ATOXIN, ATOX 
Pharmaceutical Co., 14 Old Main Road, Gillitts, 3600, South Africa). The final pooled plasma contained LPS precipitable IgG $1200 \mu \mathrm{g} / \mathrm{ml}$, according to an enzyme linked immunoassay (ELISA) (Gaffin et al., 1982a) which was precalibrated by an immunoprecipitin procedure (Gaffin et al., 1981a). The unpreserved solution of citrated plasma was bottled under laminar flow conditions and stored at $-20^{\circ} \mathrm{C}$ until used.

\section{Control plasma}

Non-immune plasma prepared as described above from horses before immunisation contained anti-LPS IgG at a concentration of $15 \cdot 0 \pm 1 \cdot 1 \mu \mathrm{g} / \mathrm{ml}$.

\section{Results}

\section{Treatment with control plasma}

As shown in fig. 1, the E. coli and Enterobacter strains treated with non-immune control plasma for $2 \mathrm{~h}$ usually appeared as separate, individual bacilli lying in a flat plane on the grid. The outer surfaces were smooth and fairly uniform. Fig. 2 shows that the Klebsiella strain formed three dimensional clumps, but also had uniform smooth outer surfaces.

\section{Anti-LPS treatment}

A few minutes after exposure to anti-LPS, the bacteria exhibited various striking morphological abnormalities. Fields of the E. coli and Enterobacter strains showed an increasing tendency towards three dimensional clumping of the previously solitary bacteria (fig. 3). The outer surfaces ap-

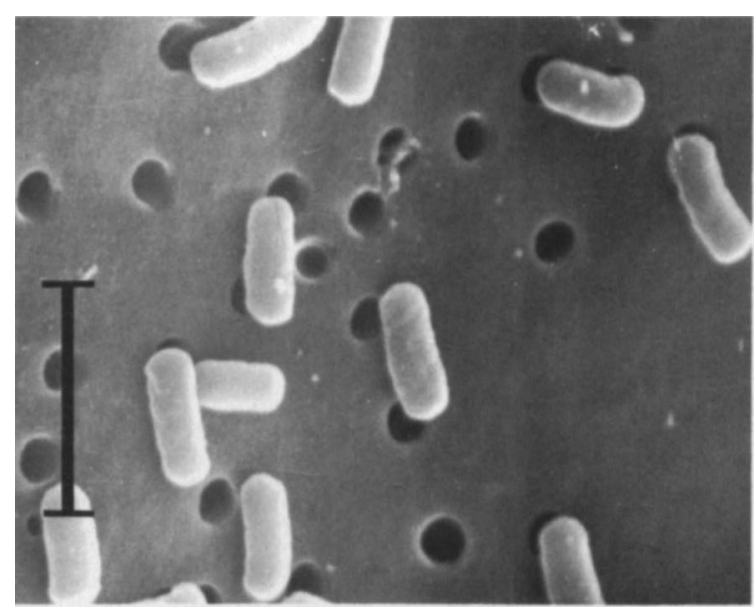

Fig. 1. SEM of $E$. coli treated with non-immune control plasma for $2 \mathrm{~h}$. The bacilli (c. $1.73 \mu \mathrm{m}$ long) show normal, smooth, uniform outer surfaces. (Bar $=3.0 \mu \mathrm{m})$

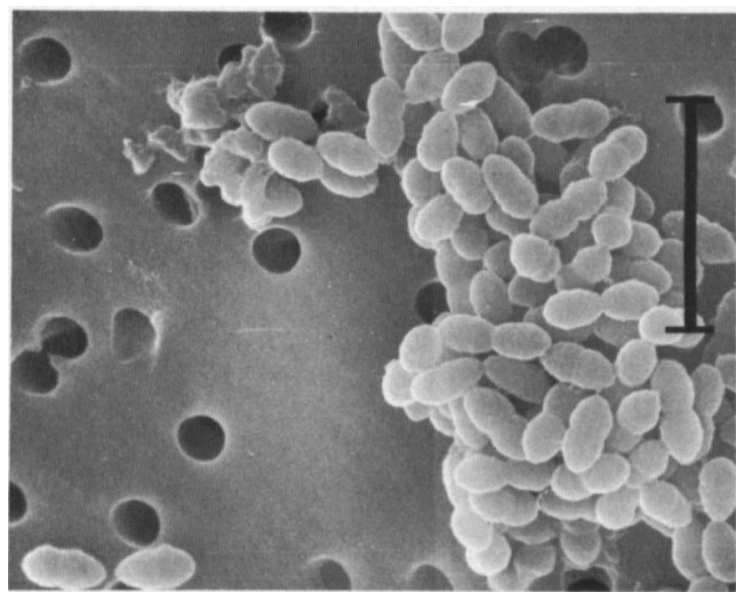

Fig. 2. SEM of $K$. pneumoniae treated with non-immune control plasma for $2 \mathrm{~h}$. Bacteria show uniform smooth outer surfaces and there is a tendency to form three dimensional clumps. $(\mathrm{Bar}=3 \cdot 0 \mu \mathrm{m})$

peared to be coated with a fibrous-like substance forming "bridges" between the bacilli. Within $3 \mathrm{~min}$ the bacilli formed extensive networks, adhering together by means of an enveloping fibrous blanket (fig. 3). Later they became slightly shrunken or collapsed and many showed extensive irregular, small, pili-like protrusions or blebs on their surfaces (fig. 4). Increasing amounts of membranous debris appeared until, after $2 \mathrm{~h}$, practically no identifiable bacteria were discernible (fig. 5).

\section{Discussion}

We previously reported that anti-LPS could cause cells of a Klebsiella strain to "agglutinate"

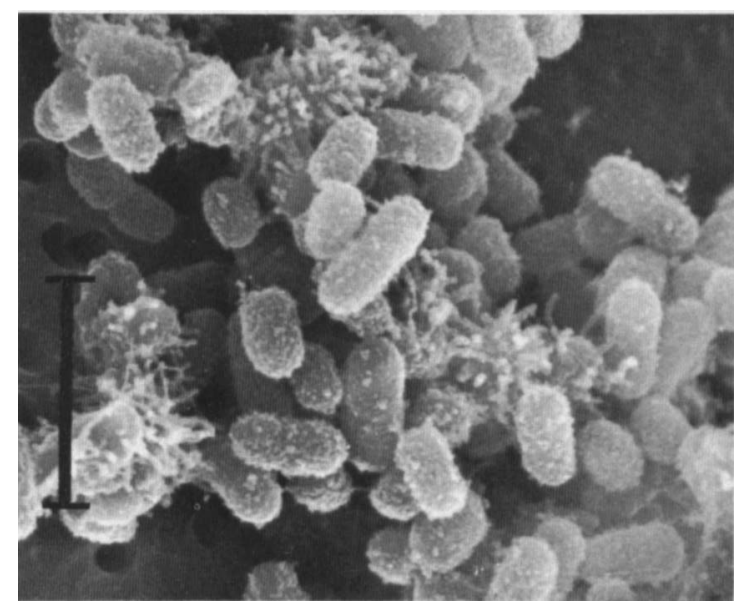

Fig. 3. SEM of $E$. coli treated with anti-LPS hyperimmune equine plasma (anti-LPS) for $3 \mathrm{~min}$. Cells appear shrunken $(0.9 \mu \mathrm{m}$ long) and are agglutinated. Note the fibrous-like blanket surrounding cells and forming bridges. (Bar $=3.0 \mu \mathrm{m}$ ) 

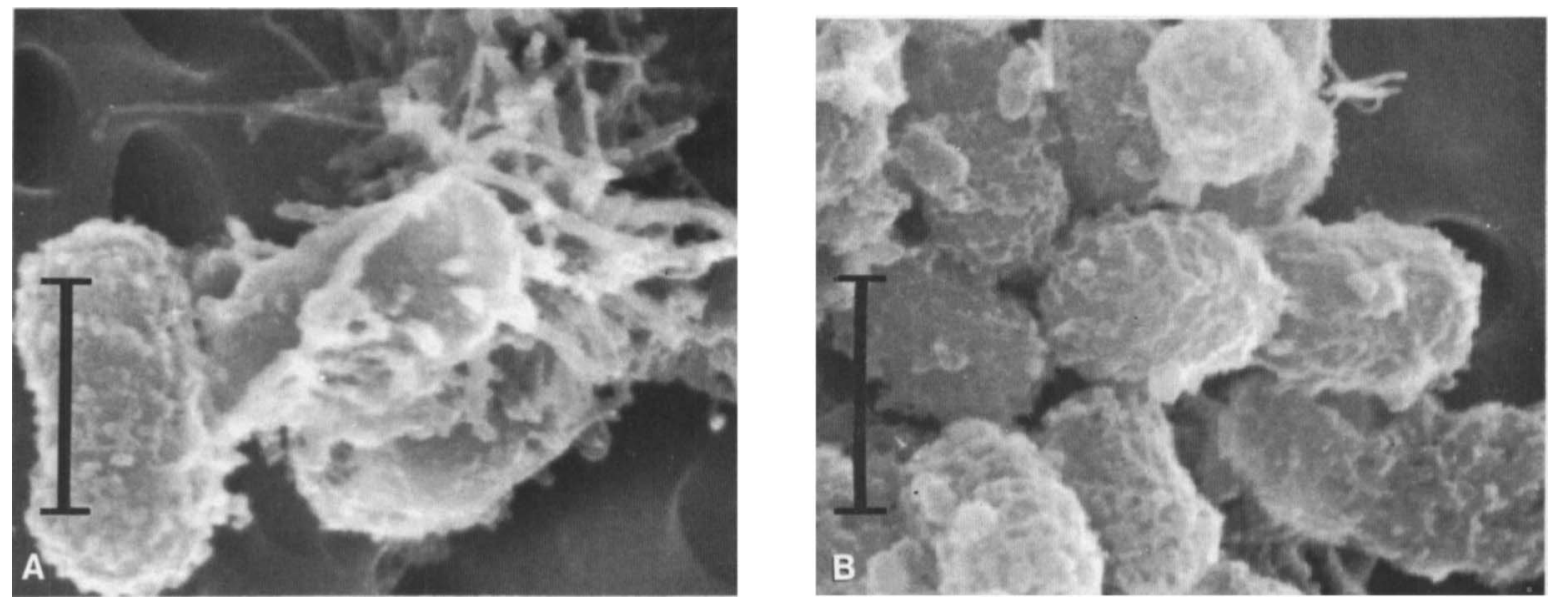

Fig. 4. SEM high magnification of E. coli (A) and Enterobacter strains treated with anti-LPS for 3 min (B). Note cell-membrane irregularities in the form of blebs and finger-like protrusions of cell membrane. $(\mathrm{Bar}=1.0 \mu \mathrm{m})$

(Gaffin et al., 1981b) and could prevent its multiplication. Transmission electronmicroscopy showed that, after anti-LPS treatment, cells of the Klebsiella strain were enlarged; the cytoplasm was less dense and disrupted membranes were present (Wells et al., 1987). In the present study, anti-LPS caused destruction of bacterial membranes, eventually

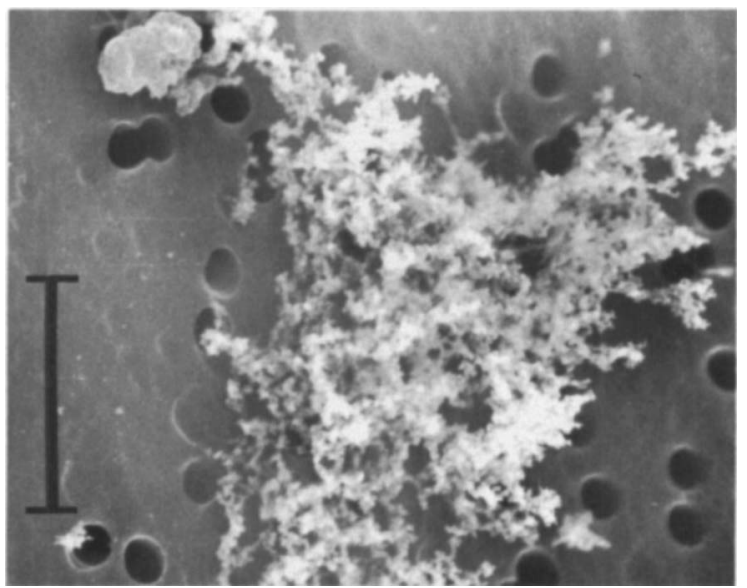

Fig. 5. SEM of $K$. pneumoniae treated with anti-LPS for $2 \mathrm{~h}$. Cell debris is present with no discernible bacterial forms. (Bar $=3 \cdot 0$ $\mu \mathrm{m})$

\section{REFERENCES}

Bayer M E 1967 Responses of cell walls of Escherichia coli to sudden reduction of environmental osmotic pressure. Journal of Bacteriology 93: 1104-1112.

Bayer M E, Remsen C C 1970 Structure of Escherichia coli after freeze-etching. Journal of Bacteriology 101 : 304-313.

Fine J 1964 Septic shock. Journal of the American Medical Association 188:427-432. leading to the almost total disintegration and digestion of the cell. Clumping and gross changes in morphology were present within $10 \mathrm{~min}$. In contrast, non-immune plasma had no effect on cell morphology.

These results are in agreement with previous reports that antibodies in hyperimmune serum and complement injure the peripheral structures of $E$. coli (Wilson and Spitznagel, 1968), forming pits or holes that might allow further action on the cytoplasmic membrane. Destruction of selective membrane permeability in the absence of osmotic stabilisers enables water to enter the cells (Bayer, 1967; Bayer and Remsen, 1970), resulting in lysis.

Anti-LPS binds to LPS, whether free in solution or in the parent bacterium. This interaction facilitates phagocytosis by neutrophils and activates complement enzymes which produce "holes" in the bacterial surface leading to lysis and disintegration. Specific IgG antibodies in anti-LPS bind to and neutralise free LPS released from these damaged bacteria.

We thank L. Maistry for excellent technical work. This work was supported by grants from the South African Medical Research Council.

Gaffin S L, Badsha N, Vorster B J, Conradie J D, Brock-Utne J G 1982a An ELISA procedure for detecting human antiendotoxin antibodies in serum. Annals of Clinical Biochemistry 19:191-194.

Gaffin S L, Grinberg Z, Abraham C, Birkham J, Schechter Y $1981 a$ Protection against hemorrhagic shock in the cat by human plasma containing endotoxin-specific antibodies. Journal of Surgical Research 31: 18-21.

Gaffin S L et al. 1981b Antibiotic effect of human and equine 
anti-endotoxin antibody-rich serum on Klebsiella pneumoniae. South African Journal of Science 78:92.

Pudifin D, L'Hoste I, Duursma J, Gaffin S L 1985 Opsonisation of gram-negative bacteria by anti-lipopolysaccharide antibodies. Lancet 2: 1009-1010.

Shenep J L, Barrett F F, Stidham G L, Westenkirscher D F, Flynn P 1985 Endotoxin liberation during therapy for gramnegative bacterial sepsis. Critical Care Medicine 13:298.

Wells M T, Gaffin S L Anti-pseudomonas activity of antilipopolysaccharide hyperimmune equine plasma. Clinical and Experimental Immunology (In press).
Wells M T, Gaffin S L, Gregory M, Coovadia Y 1987 Properties of equine anti-lipopolysaccharide hyperimmune plasma: binding to lipopolysaccharide and bactericidal activity against gram-negative bacteria. Journal of Medical Microbiology 24 : (In press).

Wilson L A, Spitznagel J K 1968 Molecular and structural damage to Escherichia coli produced by antibody, complement and lysozyme systems. Journal of Bacteriology 96:1339-1348. 